\title{
Konya'da Bir Eğitim Araştırma Hastanesi Acil Servisinde Görevli Sağlık Çalışanlarında Lateks Alerjisi ve El Egzeması Sıklığı
}

\author{
Latex Allergy and Hand Eczema Frequency in Healthcare Workers Working in a \\ Training and Research Hospital Emergency Department in Konya
}

\author{
Elif Nur YILDIRIM ÖZTÜRK (D) , Mehmet UYAR (iD , Mustafa ÖZTÜRK (iD) , Tahir Kemal ŞAHIN
}

\begin{abstract}
ÖZET
Bu çalışmada üçüncü basamak bir hastane acil servisinde çalışan sağlık çalışanlarının lateks alerjisi ve el egzeması sıklıklarının belirlenmesi ve el egzeması ile ilişkili olabilecek faktörlerin araştırılması amaçlanmıştır. Araştırma kesitsel türdedir. Acil serviste görev yapan toplam 151 doktor ve hemşireden 141'ine ulaşılmıştır. Araştırmada veri toplamak için 23 soruluk bir form kullanılmıștır. Verilerin özetlenmesinde ortalama, standart sapma, ortanca, minimum, maksimum, frekans ve yüzde dağılımları kullanılmıştır. Değişkenler arası ilişkilerin belirlenmesinde Ki-kare testinden ve bağımsız gruplarda t testin-

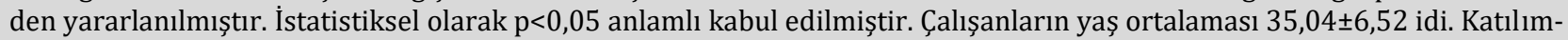
cıların \%52,9'u kadındı. Grubun \%23,4'ü doktor ve \%76,6'sı hemşire/sağlı memuru idi. Çalışmaya katılanların \% 26,4'ünden lateks alerjisi ve \%29,8'inde el egzeması mevcuttu. Egzeması olanların \%52,4'ü tedavi alıyordu ve \%88,1'inin egzeması işten uzaklaştığında azalıyordu. Araştırmada el egzeması ile cinsiyet, medeni durum, eşin çalışma durumu, evde ev işi yapma, alerji öyküsü varlığı, eldivenle geçirilen süre ve el yıkama sayısı değişkenleri arasında istatistiksel açıdan anlamlılık vardı $(\mathrm{p}<0,05)$. Araştırma sonucunda çalışanların yaklaşık dörtte birinde lateks alerjisi ve üçte birinde el egzeması bulunduğu belirlenmiştir.

Anahtar Kelimeler: Lateks alerjisi, el egzeması, sağlık çalışanı.

\section{ABSTRACT}

In this study, it is aimed to determine the frequency of latex allergy and hand eczema of healthcare workers who is working in a tertiary hospital emergency department and to investigate the factors that may be associated with hand eczema. The research is cross-sectional. 141 out of a total of 151 doctors and nurses working in the emergency department are reached. A 23-question form is used to collect data in the study. In summarizing the data, mean, standard deviation, median, minimum, maximum, frequency and percentage distributions are used. In determining the relationships between variables, Chisquare test and analysis of $t$ test in independent groups are used. Statistically $p<0.05$ is considered significant. The mean age of healthcare workers was $35.04 \pm 6.52 .52 .9 \%$ of the participants were women. $23.4 \%$ of the group were doctors and $76.6 \%$ were nurses/health officers. Of the participants in the study, $26.42 \%$ had latex allergies and $29.8 \%$ had hand eczema. $52.4 \%$ of those with eczema were receiving treatment and $88.1 \%$ of their eczema decreased when they got away from work. In the study, there were statistically significant difference between hand eczema and gender, marital status, spouse's working status, making housework, presence of allergy, time spent with gloves and hand wash number $(\mathrm{p}<0.05)$. As a result of the research, it is determined that approximately one fourth of the healthcare workers had latex allergy and one third had hand eczema.

Keywords: Latex allergy, hand eczema, healthcare worker.
\end{abstract}

Elif Nur YILDIRIM ÖZTÜRK | elifnyildirim@hotmail.com

Akşehir İlçe Sağlık Müdürlüğü, Konya, Türkiye

Mehmet UYAR I mehmetuyardr@hotmail.com

Necmettin Erbakan Üniversitesi, Meram Tıp Fakültesi, Konya, Türkiye

Mustafa ÖZTÜRK | dr.mustafa_ozturk@hotmail.com

Akşehir Devlet Hastanesi, Konya, Türkiye

Tahir Kemal ŞAHIN I tasahin@hotmail.com

Necmettin Erbakan Üniversitesi, Meram Tıp Fakültesi, Konya, Türkiye

Received/Geliş Tarihi : 28.08.2020 Accepted/Kabul Tarihi: 25.01.2021 


\section{GİRIŞ}

Doğal kauçuk lateks, bir ağacın (Hevea brasiliensis) süt kıvamındaki sıvısından elde edilir [1]. Düşük maliyet, dayanıklılık ve elastikiyet gibi özellikleri nedeniyle lateksin pek çok üründe kullanılması kaçınılmaz olmuştur [2]. Tablo 1'de lateksten üretilen ürünler sunulmuştur [1].

Tablo 1: Günlük yaşamda ve sağlık alanında kullanılan lateks ürünler [1]

\begin{tabular}{ll}
\hline Otomobil lastikleri & Tansiyon aleti manşonu \\
Yüzme gözlükleri & Steteskop \\
Tenis raketleri & Eldiven \\
Ayakkabı tabanları & Koruyucu gözlük \\
Bulaşık eldiveni & Enjektör \\
Emzik & Oral ve nazal hava yolu \\
Biberon & Endotrakeal tüp \\
Silgi & Intravenöz yol seti \\
Kondom & Dren \\
Diyafram & Katater \\
\hline
\end{tabular}

Lateks konsantrasyonu ve kuru kauçuk üretimi olmak üzere iki farklı yöntem kullanılarak kauçuk ürünleri eldesi sağlanır. Sağılı ilişkili alanlarda yaygın kullanımı olan eldiven, prezervatif ve kateter lateks konsantrasyonuyla; tüp, maske ve kanül kuru kauçuktan üretilmektedir. Lateks konsantrasyonundan üretilen ürünler, kuru kauçuktan üretilenlere kıyasla daha fazla alerjen yüküne sahiptir [3-5].

Lateks nedeniyle aşırı duyarlılık reaksiyonları ortaya çıkmaktadır. Bu reaksiyonlar immunolojik ve nonimmunolojik tip olarak iki farklı şekilde görülebilir. İmmunolojik hücresel gecikmiş tipte lateks materyalle temas eden cilt bölgelerinde 24-48 saat içinde ortaya çıkan sulanan kabarık lezyonlar söz konusudur [1]. İmmunolojik Ig E aracılı tipte lateks temasının ardından dakikalar içinde kontakt ürtiker ortaya çıkabilir. Lateks alerjisinin en korkutucu ve yaşamı tehdit eden hali ürtiker, anjioödem ve bronkospazmla kendini gösteren anaflaksidir $[1,6]$. Nonimmunolojik tip alerji, lateks alerjileri içerisinde en yaygın olanıdır. Gerçek bir alerjiden öte tahrişle ilişkilidir. Genellikle ellerde ortaya çıkar ve derinin kuru, kızarık ve kaşıntılı olması tipiktir [1].
Genel popülasyonda lateks alerjisinin \%1'in altında [5] olduğunu söyleyen kaynaklar olduğu gibi $\% 5$ civarında [7] ve \%2-10 arasında [1] olduğunu belirten kaynaklar da mevcuttur. Atopik yapıya sahip olanlar, lateksle sık temas eden sağlık çalışanları, kuaförler/berberler, temizlik işçileri, lateks üretiminde görev alanlar, sık mesane kateterizasyonu gerektiren rahatsızlı̆ı bulunanlar, nöral tüp defekti olanlar (spina bifida gibi) ve sık opere olanlarda lateks alerjisi daha sık izlenmektedir. Sağlık çalışanlarında lateks alerji sıklığını \%17’ye kadar bildiren kaynaklar mevcuttur $[1,5]$.

El egzeması irritan kontakt dermatit, alerjik kontakt dermatit ve atopik el dermatiti gibi çeşitli etiyolojiler ile ilişkili olarak ortaya çıkan bir durumdur. Ellerde kaşıntı, ağrı, kızarıklık, vezikül, papül, pullanma ve hiperkeratöz gözlenir $[8,9]$.

Kişilerin \%2-10'unun yaşam boyu el egzeması yaşama riski söz konusudur [10].

Bu çalışma ile üçüncü basamak bir hastane acil servisinde çalışan sağlık çalışanlarının lateks alerjisi ve el egzeması sıklıklarının belirlenmesi ile el egzeması ile ilişkili olabilecek faktörlerin araşıtııılması amaçlanmıştır.

\section{YÖNTEM}

\section{A. Araştırmanın Türü}

Araştırma kesitsel türde tasarlanmış bir epidemiyolojik çalışmadır.

\section{B. Araştırma İzinleri}

Araştırmanın yapılabilmesi için Necmettin Erbakan Üniversitesi Meram Tıp Fakültesi İlaç ve Tıbbi Cihaz Dışı Etik Kurulu'ndan etik izin (Tarih: 05.01.2018 Sayı: 2017/1143) ve Konya İl Sağlık Müdürlügü̈̈nden kurum izni alınmıştır. 


\section{Araştırmanın Yapıldı̆̆ı Yer}

Araştırmanın yapıldığı hastane Meram ilçesinde bulunmaktadır ve 3. basamak bir hastanedir. Araştırma için bu hastanenin tercih edilme nedeni en fazla sayıda günlük hasta girişi olan ve en fazla sayıda sağlık çalışanını bünyesinde bulunduran acil servise sahip olmasıdır. Hastane acil servisinde 24 saatlik sürede 1200-1300 civarında hastaya hizmet verilmektedir. Acil serviste yeşil alan, gözlem (23 yataklı), sarı alan (7 yataklı), travma (4 yataklı) ve resüsitasyon (3 yataklı) bölümlerine ek olarak birisi toksikoloji (6 yataklı) ve diğeri acil kritik (11 yataklı) olmak üzere iki tane yoğun bakım vardır. Bu alanların tümünde doktor ve hemşirelerin erişimine açı toplam 16 lavabo ve 30 alkollü el dezenfektanı bulunmaktadır.

\section{Araştırmanın Evreni}

Araştırmanın evrenini 1 Aralık 2019-31 Ocak 2020 tarihleri arasında acil serviste görev yapan toplam 151 doktor ve hemşire oluşturmuştur. Araştırma kapsamında örneklem seçimine gidilmemiş olup evrenin tamamına ulaşılması hedeflenmiştir. Toplam 10 doktor ve hemşire araştırmaya katılmayı kabul etmemiş olup toplam katılımcı sayısı 141 (katılımcı yüzdesi=93,3) kişi olmuştur.

\section{E. Araştırmada Kullanılan Veri Toplama Formu ve}

\section{Verilerin Toplanması}

Araştırmada veri toplamak için, araştırmacılar tarafından literatür taranarak 23 sorudan ve 2 temel bölümden oluşan bir anket formu geliştirilmiştir. Katılımcıların sosyodemografik özellikleri birinci bölümde ve el yıkama, eldiven kullanımı, alerji ve el egzeması ile ilgili özellikleri ikinci bölümde sorgulanmıştır. Anketin ön uygulaması, araştırma öncesi 10 gönüllü sağlık çalışanı ile yapılmıştır. Ön uygulama ile veri toplama aracında yer alan soruların anlaşır ve araştırmada istenen verileri toplamak için yeterli olduğu görülmüştür.
1 Aralık 2019-31 Ocak 2020 tarihleri arasından katılımcılara araştırmacılar tarafından araştırma hakkında bilgi verilmiş ve sözlü onamları alındıktan sonra hazırlanan form, araştırmacıların katılımcıları gözlem alında tutacağı biçimde uygulanmıştır. Her bir anket için doldurma süresi ortalama 15 dakikadır.

\section{F. İstatistiksel Analiz}

Veri girişi, istatistiksel analiz ve rapor yazım işlemleri bilgisayar ortamında gerçekleştirilmiştir. Sayısal verilerin özetlenmesinde ortalama, standart sapma, ortanca, minimum ve maksimum değerleri; kategorik verilerin özetlenmesinde frekans ve yüzde dağılımları kullanılmıştır. Değişkenler arası ilişkilerin belirlenmesinde Ki-kare testinden ve bağımsız gruplarda t testinden yararlanılmıştır. İstatistiksel olarak p<0,05 anlamlı kabul edilmiştir.

\section{BULGULAR}

\section{A. Sağlık Çalışanlarının Sosyodemografik Özellikleri}

Toplam 141 sağlık çalışanının yaş ortalaması $35,04 \pm 6,52$ ve yaş ortancası 35 (24-55) idi. Katılımcıların bazı sosyodemografik özellikleri Tablo 2'de sunulmuştur.

Tablo 2: Sağlık çalışanlarının bazı sosyodemografik özellikleri

\begin{tabular}{llcc}
\hline & Özellikler & $\mathbf{n}$ & $\mathbf{\%}$ \\
\hline \multirow{2}{*}{ Cinsiyet } & Kadın & 74 & 52,9 \\
& Erkek & 66 & 47,1 \\
\hline \multirow{2}{*}{ Medeni durum } & Bekar/Boşanmış & 53 & 37,6 \\
& Evli & 88 & 62,4 \\
\hline \multirow{2}{*}{ Eşin çalışma durumu } & Çalışıyor & 91 & 64,5 \\
& Çalışmıyor & 23 & 25,8 \\
\hline \multirow{2}{*}{ Meslek } & Doktor & 33 & 23,4 \\
& Hemşire/Sağlık Memuru & 108 & 76,6 \\
\hline \multirow{3}{*}{ Eğitim durumu } & Lise & 21 & 14,9 \\
& Ön lisans & 29 & 20,6 \\
Çocuk sahibi olma durumu & Lisans & 91 & 64,5 \\
\hline Çocuğun bakımına yardım & Var & 83 & 59,3 \\
eden birinin varlığı & Yok & 57 & 40,7 \\
\hline \multirow{3}{*}{ Evde temizlik, yemek gibi } & Yok & 34 & 41,5 \\
gündelik işlerin yapılması & Een yapıyorum yapıyor & 48 & 58,5 \\
\hline & Diğer ve ben yapıyoruz & 50 & 36,0 \\
& & 30 & 21,6 \\
\hline
\end{tabular}


Tablo 3: Sağlık çalışanlarının el yıkama, eldiven kullanımı, alerji ve el egzeması ile ilgili bazı özellikleri

\begin{tabular}{|c|c|c|c|}
\hline \multicolumn{2}{|l|}{ Özellikler } & \multirow{2}{*}{$\begin{array}{c}\mathrm{n} \\
96\end{array}$} & \multirow{2}{*}{$\frac{\%}{68,1}$} \\
\hline & Evet & & \\
\hline 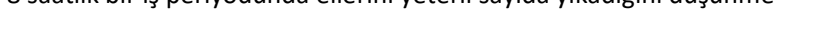 & Hayır & 45 & 31,9 \\
\hline \multirow{4}{*}{ El yıkama sırasında en sık kullanılan malzeme } & Antiseptik solüsyon & 15 & 10,8 \\
\hline & Sivi sabun & 120 & 86,3 \\
\hline & Sadece su & 2 & 1,4 \\
\hline & Diğer & 2 & 1,4 \\
\hline \multirow{2}{*}{8 saatlik bir iş periyodunda yeterli sayıda eldiven kullandığını düşünme } & Evet & 105 & 74,5 \\
\hline & Hayır & 36 & 25,5 \\
\hline \multirow{4}{*}{8 saatlik bir iş periyodunda kullanılan yaklaşık eldiven sayısı } & 5 çiftten az & 3 & 2,2 \\
\hline & 5-15 çift & 37 & 27,2 \\
\hline & 16-30 çift & 47 & 34,6 \\
\hline & 30 çiftten fazla & 49 & 36,0 \\
\hline \multirow{5}{*}{8 saatlik bir iş periyodunda eldivenle geçirilen yaklaşık süre } & 1 saatten az & 39 & 27,9 \\
\hline & 1-2 saat arası & 37 & 26,4 \\
\hline & 3-4 saat arası & 44 & 31,4 \\
\hline & 5-6 saat arası & 17 & 12,1 \\
\hline & 7-8 saat arası & 3 & 2,1 \\
\hline \multirow{2}{*}{ Herhangi bir şeye karşı alerji durumu } & Var & 43 & 30,5 \\
\hline & Yok & 98 & 69,5 \\
\hline \multirow{2}{*}{ Ailede bilinen bir alerji öyküsü } & Var & 40 & 28,8 \\
\hline & Yok & 99 & 71,2 \\
\hline \multirow{2}{*}{ Lateks alerjisi } & Var & 37 & 26,4 \\
\hline & Yok & 103 & 73,6 \\
\hline \multirow{2}{*}{ Ellerde egzema varlığı } & Var & 42 & 29,8 \\
\hline & Yok & 99 & 70,2 \\
\hline \multirow{2}{*}{ Egzema için tedavi alma } & Alıyor & 20 & 47,6 \\
\hline & Almıyor & 22 & 52,4 \\
\hline \multirow{3}{*}{ İşten ve iş yerinden uzaklaşthğında egzemanın durumu } & Azalıyor & 37 & 88,1 \\
\hline & Aynı kalıyor, değişmiyor & 3 & 7,1 \\
\hline & Artiyor & 2 & 4,8 \\
\hline
\end{tabular}

Sağlık çalışanlarının meslekte toplam çalışma süresi ortalaması 9,36 $\pm 6,43$ yıl ve ortancası 8 (1-32) idi. Katılımcıların bir ay içerisindeki çalışma süreleri ortalaması $198,30 \pm 51,05$ saat ve ortancas1 180 (32-340) idi.

\section{B. Sağlık Çalışanlarının El Yıkama, Eldiven Kullanımı,} Alerji ve El Egzeması ile İlgili Özellikleri

Çalışanların 8 saatlik bir iş periyodunda el yıkama sayısı ortalaması $17,07 \pm 10,95$ ve ortancası 15 (1-50) idi. Sağlık çalışanlarının el yıkama, eldiven kullanımı, alerji ve el egze- ması ile ilgili bazı özellikleri Tablo 3'te sunulmuştur.

C. Sağlık Çalışanlarının El Egzeması ile İlişkili Olabilecek Özelliklerinin Araştırılması

Sağlık çalışanlarının el egzeması ile ilişkili olabilecek özelliklerinin araştırılması amacıyla yapılmış olan Ki-kare testi sonuçları Tablo 4'te ve t testi sonuçları Tablo 5'tedir.

Meslek, eğitim durumu, çocuk sahibi olma durumu, çocuğun bakımına yardım eden birinin varlığı, el yıkama 
Tablo 4: Sağlık çalışanlarının el egzeması ile ilişkili olabilecek bazı kategorik özellikleri

\begin{tabular}{|c|c|c|c|c|c|c|c|}
\hline \multirow{3}{*}{\multicolumn{2}{|c|}{ Değişkenler }} & \multicolumn{4}{|c|}{ Ellerde egzema varlığı } & \multirow{3}{*}{ Ki-kare } & \multirow{3}{*}{$\mathbf{p}$} \\
\hline & & \multicolumn{2}{|c|}{ Var } & \multicolumn{2}{|c|}{ Yok } & & \\
\hline & & $\mathrm{n}$ & $\%$ & $\mathbf{n}$ & $\%$ & & \\
\hline \multirow{2}{*}{ Cinsiyet } & Kadın & 32 & 43,2 & 42 & 56,8 & \multirow{2}{*}{11,806} & \multirow{2}{*}{0,001} \\
\hline & Erkek & 10 & 15,2 & 56 & $84,8^{*}$ & & \\
\hline \multirow{2}{*}{ Medeni durum } & Bekar/Boşanmış & 10 & 18,9 & 43 & $81,1^{*}$ & \multirow{2}{*}{4,041} & \multirow{2}{*}{0,044} \\
\hline & Evli & 32 & 36,4 & 56 & 63,6 & & \\
\hline \multirow{2}{*}{ Eşin çalışma durumu } & Çalışıyor & 29 & 43,9 & 37 & 56,1 & \multirow{2}{*}{5,792} & \multirow{2}{*}{0,016} \\
\hline & Çalışmıyor & 3 & 13,0 & 20 & $87,0^{*}$ & & \\
\hline \multirow{4}{*}{$\begin{array}{l}\text { Evde temizlik, yemek gibi gündelik işlerin } \\
\text { yapılması }\end{array}$} & Ben yapıyorum & 13 & 26,0 & 37 & 74,0 & \multirow{4}{*}{9,728} & \multirow{4}{*}{0,021} \\
\hline & Eşim yapıyor & 4 & 13,3 & 26 & $86,7^{*}$ & & \\
\hline & Eşim ve ben yapıyoruz & 12 & 50,0 & 12 & 50,0 & & \\
\hline & Diğer & 13 & 37,1 & 22 & 62,9 & & \\
\hline \multirow{2}{*}{ Herhangi bir şeye karşı alerji durumu } & Var & 24 & 55,8 & 19 & 44,2 & \multirow{2}{*}{18,288} & \multirow{2}{*}{0,001} \\
\hline & Yok & 18 & 18,4 & 80 & $81,6^{*}$ & & \\
\hline \multirow{2}{*}{ Lateks alerjisi } & Var & 19 & 51,4 & 18 & 48,6 & \multirow{2}{*}{9,579} & \multirow{2}{*}{0,002} \\
\hline & Yok & 23 & 22,3 & 80 & $77,7^{*}$ & & \\
\hline \multirow{2}{*}{$\begin{array}{l}8 \text { saatlik bir iş periyodunda eldivenle geçirilen } \\
\text { yaklaşık süre }\end{array}$} & 1 saatten az & 17 & 43,6 & 22 & 56,4 & \multirow{2}{*}{3,899} & \multirow{2}{*}{0,048} \\
\hline & 1 saat ve üzeri & 25 & 24,8 & 76 & $75,2^{*}$ & & \\
\hline
\end{tabular}

*Farkı oluşturan gruba işaret etmektedir.

Tablo 5: Sağlık çalışanlarının el egzeması ile ilişkili olabilecek bazı sayısal özellikleri

\begin{tabular}{|c|c|c|c|c|c|c|}
\hline Değişkenler & Ellerde egzema varlığı & $\mathbf{n}$ & Ortalama & Standart sapma & $t$ istatistiği & p \\
\hline \multirow{3}{*}{ Yaş } & Yok & 97 & 34,7835 & 6,88481 & \multirow{3}{*}{$-0,712$} & \multirow{3}{*}{0,478} \\
\hline & & & & & & \\
\hline & Var & 42 & 35,6429 & 5,62148 & & \\
\hline \multirow{3}{*}{ Meslekte toplam çalışma süresi } & Yok & 97 & 8,9588 & 6,58268 & \multirow{3}{*}{$-1,149$} & \multirow{3}{*}{0,252} \\
\hline & & & & & & \\
\hline & Var & 39 & 10,3590 & 6,00652 & & \\
\hline \multirow{3}{*}{ Aylık çalışma süresi } & Yok & 95 & 199,9789 & 51,67842 & \multirow{3}{*}{0,589} & \multirow{3}{*}{0,557} \\
\hline & & & & & & \\
\hline & Var & 40 & 194,3000 & 49,92569 & & \\
\hline \multirow{2}{*}{$\begin{array}{l}8 \text { saatlik bir iş periyodunda el } \\
\text { yıkama sayısı }\end{array}$} & Yok & 81 & 15,5432 & 9,45654 & \multirow{2}{*}{$-2,051$} & \multirow{2}{*}{0,046} \\
\hline & Var & 34 & 20.7059 & 13,33832 & & \\
\hline
\end{tabular}

sırasında en sık kullanılan malzeme, 8 saatli bir iş periyodunda kullanılan yaklaşık eldiven sayısı, ailede bilinen bir alerji öyküsü gibi diğer değişkenlerle el egzeması varlığı arasında istatistiksel açıdan anlamlı ilişki belirlenmedi $(\mathrm{p}>0,05)$.

\section{TARTIŞMA}

Araştırma grubunun \%26,4’ü kendisinde lateks alerjisi olduğunu ifade etmiştir. Ardeniz ve arkadaşlarının 219 kişi ile gerçekleştirdikleri çalışmalarında deri testi ile sağlık çalışanlarında lateks alerji sıklığı \%28,6'dır [11]. Sarıcaoğlu ve arkadaşlarının çalışmasında \%46'lık sıklık belirlenmiştir [12]. Köse ve arkadaşlarının 1115 sağlık çalışanıyla yaptıkları çalışmada deri ve kan testleriyle lateks alerji sıklığı \% 4,2 bulunmuştur [2]. Çin'de 8485 hemşireyle yapılan bir çalışmada sıklık \%8,8 [13]; Tayland’da 4529 sağlık çalışa- 
nının katıldığı bir araştırmada \%13,3 [14]; Amerika Birleşik Devletleri'nde 804 sağlık çalışanıyla yapılan bir araştırmada \%5 [15]; İspanya'da 620 sağlık çalışanının katılımıyla gerçekleştirilen bir çalışmada \%5,9 [16] ve İran'da 104 sağlık çalışanıyla yürütülen araştırmada \%17,9 [17] bulunmuştur. Wu ve arkadaşları çeşitli çalışmalardan derledikleri oranlarla sağlık çalışanlarında lateks alerji sıklığını \%9,7 olarak raporlamışlardır [7]. Araştırmamızda bulunan sıklık literatürdeki bazı diğer sıklıklardan yüksektir. Bu durum üzerinde çalışılan grubun acil servis çalışanı olmasıyla ve başta eldiven olmak üzere lateks içeren ürünlere sık sık ve uzun süreli maruziyetiyle açıklanabilir. Ayrıca çalışmanın yapıldığı grubun bireysel özellikleri de bir etken olabileceği için, değerlendirme sırasında dikkate alınmalıdır.

Araştırma grubunun \%29,8'i ellerinde egzema bulunduğunu belirtmiştir. Güney İsveç'te 9051 sağlık çalışanını içeren 12288 kişi ile yapılmış bir araştırmada katılımcıların \%21'i el egzeması olduğunu beyan etmiştir [18]. 20142018 yılları arasında yama testi ile değerlendirilmiş olan 56170 hastanın \%29,9’u el egzemasından muzdarip olduğu saptanmıştır [19]. Ayrıca kişilerin \%2-10'unun yaşam boyu el egzeması yaşama riskinin söz konusu olduğu bilinmektedir [10]. Hem araştırmamız hem de literatürdeki diğer çalışmalar sağlık çalışanlarının el egzemasına maruziyet sıklığının daha yüksek olduğunu göstermekte ve doğrulamaktadır. Bu durum sağlık ilişkili mesleklerin sık el yıkama ve eldiven kullanımı başta olmak üzere gerektirdiklerinden kaynaklanıyor olabilir.

Araştırmamızda el egzemasıyla ilişkili değişkenler saptanmıştır. Erkek olma, bekar/boşanmış olmak, eşin çalışmaması, ev işlerini eşin yapması, herhangi bir şeye alerjisi olmaması, lateks alerjisi olmaması ve günlük çalışma süresinde bir saatten fazla eldiven kullanma özelliklerine sahip kişilerde el egzeması görülmemekte veya daha az görülmektedir. Bununla birlikte el egzeması olanların el yıkama sayı- larının olmayanlara kıyasla anlamlı şekilde yüksek olduğu bulunmuştur. Çavuş ve arkadaşları Denizlìde 236 sağlık çalışanıyla yaptıkları araştırmalarında araştırmamızdakine benzer risk faktörleri tanımlamışlardır [20]. Bu durumların tamamı egzemaya yol açabilecek etkenlere maruz kalma ile ilişkilendirilebilir. Literatürde ise el egzeması meslekle ve irritan etkenlerle ilişkilendirilmektedir [18, 19].

\section{SONUÇ}

Araştırma sonucunda kişilerin \%26,4’ünde lateks alerjisi ve \%29,8'inde el egzeması olduğu belirlenmiştir. Cinsiyet, medeni durum, eşin çalışma durumu, evde ev işi yapma, alerji öyküsü varlığı, eldivenle geçirilen süre ve el yıkama sayısı değişkenleri ile el egzeması arasında ilişki olduğu saptanmıştır.

Sağlık alanında çalışan kişilerde lateks alerjisi ve el egzeması daha sık gözlenmektedir. Bu alanda görev yapan kişilerin alerjen ve irritan maruziyetini azaltacak önlemlerin hem bireysel hem de kurumsal düzeyde alınması gerekmektedir.

YazAr KatkılaARI: Araştırma fikrinin oluşturulması, tasarımı ENYÖ, MU, MÖ, TKŞ; veri toplanması ENYÖ, MÖ; analiz, yorum ve makalenin raporlanması ise ENYÖ, MU, MÖ, TKŞ tarafından yapılmıştır.

Çı́kAR ÇATişması: Yazarlar herhangi bir çıkar çatışması olmadığını, makalede araştırma ve yayın etiğine uyulduğunu beyan ederler.

Finansal Destek: Bu çalışmada herhangi bir kişi, kurum veya kuruluştan finansal destek alınmamıştır.

Етік Комітте Onayı: Çalışma için 05.01.2018 tarihinde 2017/1143 numarası ile Necmettin Erbakan Üniversitesi İlaç ve Tıbbi Cihaz Dışı Araştırmalar Etik Kurulu’ndan onay alınmıştır. 


\section{KAYNAKÇA}

[1] Kırmaz, C. (2011). Sağlık kurumlarında lateks alerjisi ve alınması gereken önlemler. 7. Ulusal Sterilizasyon Dezenfeksiyon Kongresi Bildiri Kitabı, 269-274.

[2] Köse, Ş., Mandıracioğlu, A., Tatar, B., Gül, S. \& Erdem, M. (2014). Sağlık çalışanlarında lateks alerjisi görülme sıklığı İzmir, (Türkiye). Cent Eur J Public Health (Halk Sağlığı), 22(4): 262-265.

[3] Walls, R.S. (1996). Latex allergy: A real problem. Med J Aust, 164: 707-708.

[4] Blanco Guerra, C., Quirce Gancedo, S., De la Hoz Caballer, B., Nieto Garcia, A. \& Tabar Purroy, A. (2007). Reacciones de hipersensibilidad al latex del arbol del caucho. In: Tratado de alergologia. Editores Pelaez, Davila. Ergon, 1657-1680.

[5] Atakul, G. \& Asilsoy, S. (2017). Lateks alerjisi. Klinik Tip Pediatri Dergisi, 9(2): 160-164.

[6] Koyuncu, A. \& Eti Aslan, F. (2014). Sağlık bakımında görünmeyen tehlike; plastik ürünler ve etkileri. Anadolu Hemşirelik ve Sağlık Bilimleri Dergisi, 17 (2): 117-124.

[7] Wu, M., McIntosh, J. \& Liu, J. (2016). Current prevalence rate of latex allergy: Why it remains a problem? Journal of occupational health, 58(2): 138144.

[8] Coenraads, P.J. (2012). Hand eczema. N Engl J Med, 367:1829-1837.

[9] Çakar, N., Bilgin, M.D., Tamam, Y. \& Nazlıkul, H. (2019). Kortizon uygulamasına dirençli el egzama tedavisinde düzenleyici yöntemler: Olgu sunumu. Bilimsel Tamamlayıcı Tıp, Regülasyon ve Nöralterapi Dergisi, 13(2): 36-39.

[10] Agarwal, U.S., Besarwal, R.K., Gupta, R., Agarwal, P. \& Napalia, S. (2014). Hand eczema. Indian J Dermatol, 59: 213-224.

[11] Ardeniz, Ö., Mete, N., Sin, A., Kokuludağ, A. \& Sebik, F. (2004). Atopik ve nonatopik hastane personelinde lateks duyarlılığı. Ege Tip Dergisi, 43(1): 1-7.

[12] Sarıcaoğlu, H., Ovalı Toka, S. \& Algan, S.İ. (2013). Sağlık çalışanlarında lateks alerjisi. Türkderm, 47: 9498.

[13] Liu, Q.L., He, X.Z., Liang, K., Xie, R., Fang, H.P., Zhu, K.J. \& Fan, Y.M. (2013). Prevalence and risk factors for latex glove allergy among female clinical nurses: A multicenter questionnaire study in China. Int J Occup Environ Health, 19: 29-34.

[14] Boonchai, W., Sirikudta, W., Iamtharachai, P. \&
Kasemsarn, P. (2014). Latex glove-related symptoms among health care workers: A selfreport questionnaire -based survey. Dermatitis, 25: 135-139.

[15] Wang, M.L., Kelly, K.J., Klancnik, M. \& Petsonk, E.L. (2012). Self-reported hand symptoms: A role in monitoring health care workers for latex sensitization? Ann Allergy Asthma Immunol, 109: 314-318.

[16] Galindo, M.J., Quirce, S. \& Garcia, O.L. (2011). Latex allergy in primary care providers. J Investig Allergol Clin Immunol, 21: 459-465.

[17] Nabavizadeh, S.H., Anushiravani, A. \& Amin, R. (2009). Natural rubber latex hypersensitivity with skin prick test in operating room personnel. Iran J Allergy Asthma Immunol, 8: 219-220.

[18] Hamnerius, N., Svedman, C., Bergendorff, O., Björk, J., Bruze, M. \& Ponten, A. (2018). Wet work exposure and hand eczema among healthcare workers: A cross-sectional study. British Journal of Dermatology, 178: 452-461.

[19] Mahler, V \& Dickel, H. (2019). Wichtigste Kontaktallergene beim Handekzem/Most important contact allergens in hand eczema. Der Hautarzt, 70: 778789.

[20] Çavuş, Ş., Gümüş, R.O., Koral, F. \& Ergin, Ş. (2012). Pamukkale Üniversitesi Eğitim, Sağlık ve Araştırma Merkezi sağlık çalışanlarında el ekzeması görülme sıklığı. Anatol J Clin Investig, 6(1): 221224. 